\title{
MAGNET DESIGN AND BEAM DYNAMICS IN COMPUTED FIELDS FOR DC-350 CYCLOTRON
}

\author{
N. Yu. Kazarinov, M. N. Sazonov \\ Joint Institute for Nuclear Research, Dubna
}

The paper describes the results of 3D magnets simulation. The cyclotron magnet and analyzing bending magnet IM-90 of axial injection chanell are studied here. The influence of correction coils for cyclotron magnet is calculated. All magnetic fields have been calculated by MERMAID 3D code [1].

Представлены результаты 3D-моделирования магнита для циклотрона DC-350. Даны оценки влияния корректирующих катушек. Показаны результаты моделирования анализирующего магнита канала аксиальной инжекции с учетом динамики пучка в полученных полях. Все расчеты проведены с помощью пакета программ MERMAID.

PACS: 29.20.dg

\section{DC-350 MAIN MAGNET}

The cyclotron magnet has a classical $\mathrm{H}$ shape, the gaps between valley and sectors are 400 and $240 \mathrm{~mm}$, correspondingly. The magnet parameters are shown in Table 1.

Due to symmetry of the magnet the $90^{\circ}$ model has been used to simulate magnetic fields. The $90^{\circ}$ model is $1 / 8$ part of magnet. The magnet yoke has been optimized by using this model. The shape of final magnet is displayed in Fig. 1.

The influence of bended edges is about $50 \mathrm{Gs}$ at high level of average magnetic field $1.5 \mathrm{~T}$.

Table 1. Magnet specifications

\begin{tabular}{|l|c|}
\hline Pole radius, $\mathrm{m}$ & 2 \\
\hline Extraction radius, $\mathrm{m}$ & 1.76 \\
\hline Average magnetic fields, $\mathrm{T}$ & 1.24 to 1.5 \\
\hline Number of sectors & 4 \\
\hline Dimensions, $\mathrm{m}$ & $5 \times 4.7 \times 9.1$ \\
\hline Weight, $\mathrm{t}$ & about 1100 \\
\hline
\end{tabular}




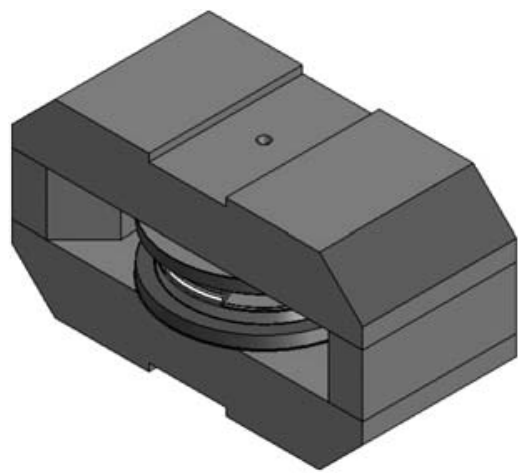

Fig. 1. Main magnet of cyclotron DC-350

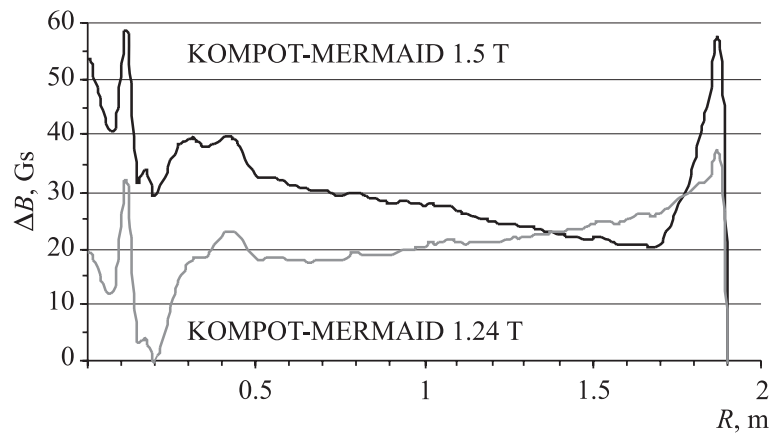

Fig. 2. Comparison of independent simulations with $90^{\circ}$ magnet model

The result of calculated magnetic fields by $90^{\circ}$ model has been compared with the results obtained by our colleagues from Efremov Institite by KOMPOT code [2]. The difference between independent simulations is presented in Fig. 2.

For both levels of average magnetic field 1.5 and $1.24 \mathrm{~T}$ the difference is less than $50 \mathrm{Gs}$.

\section{CORRECTION COILS}

There are nine radial correction coils $\mathrm{C} 0-\mathrm{C} 8$ for DC-350 cyclotron magnet (see Fig. 3). The correction coils are required for adjusting magnetic fields of constructed magnet.

The net effect of each correction coil has been calculated as difference between magnetic fields. One set is magnetic fields calculated with coil and another one is pure magnetic field of main magnet. Thus, a bunch of computations has been done to get influence of all correction coils at all levels of magnetic field.

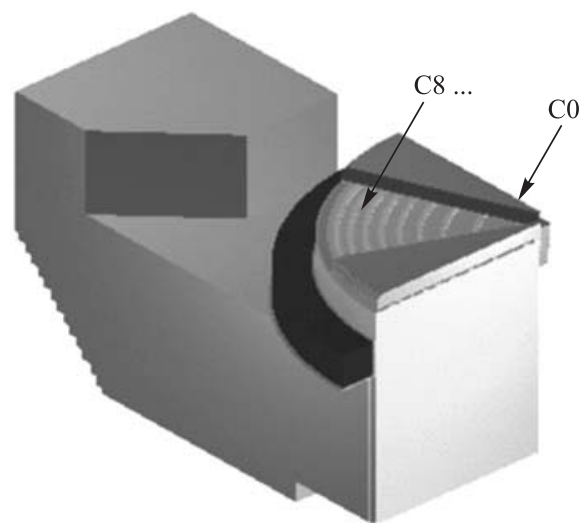

Fig. 3. The $90^{\circ}$ magnet model with correction coils 


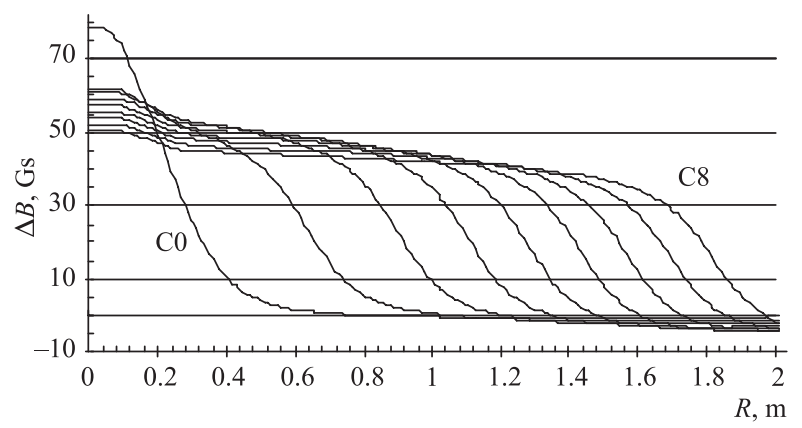

Fig. 4. Net effect of correction coils at average magnetic field $1.5 \mathrm{~T}$

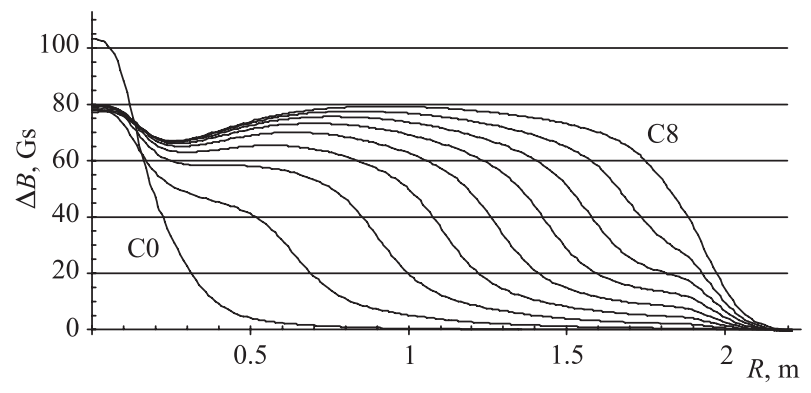

Fig. 5. Net effect of correction coils at average magnetic field $1.24 \mathrm{~T}$

The coils C1-C7 have been designed to have maximal total current $960 \mathrm{~A} /$ turns, while the coil $\mathrm{C} 0$ of central region has $1500 \mathrm{~A} /$ turns. The results of net influence of the correction coils are shown in Figs. 4 and 5.

The symmetric results have been calculated for reverse current of correction coils. The net effects to average magnetic field are more than $40 \mathrm{Gs}(1.5 \mathrm{~T})$ and more than $60 \mathrm{Gs}(1.24 \mathrm{~T})$ for each coil.

\section{IM-90 MAGNET}

The ion beams after superconducting ESR ion source come into analyzing bending magnet IM-90. It is a start of axial injection channel of DC-350 cyclotron. The geometry of simulated magnet is shown in Fig. 6.

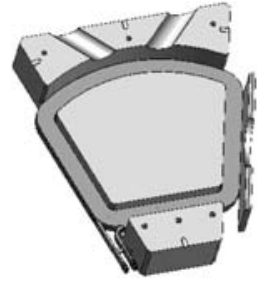

Fig. 6. Geometry of bending magnet IM-90

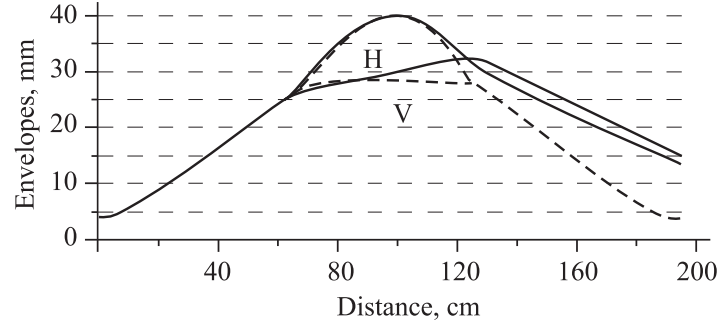

Fig. 7. Beam envelopes for angle $\xi=29.5^{\circ}$ 
Table 2. IM-90 magnet parameters

\begin{tabular}{|l|c|}
\hline Ion mass-to-charge ratio $A / Z$ & $5-10$ \\
\hline Accelerating voltage, $\mathrm{kV}$ & 25 \\
\hline Beam bending angle, $^{\circ}$ & 90 \\
\hline Radius of beam trajectory, $\mathrm{mm}$ & 350 \\
\hline Gap between magnet pole, $\mathrm{mm}$ & 120 \\
\hline Magnetic field, $\mathrm{T}$ & $0.184( \pm 1 \%)$ \\
\hline Distortion of magnetic field at beam area, $\mathrm{mm}$ & $\Delta R= \pm 60\left(\Delta B / B<10^{-3}\right)$ \\
\hline
\end{tabular}

The magnet has shield screens at beam entrance and at beam exit. Due to magnet symmetry the $1 / 4$ part of magnet has been simulated. The parameters of IM-90 magnet are shown in Table 2.

The design of magnet includes bunch dynamics in calculated fields. The beam dynamics has been estimated with linear approximation.

The geometry of magnet has been chosen by changing the angle between beam trajectory normal and magnet pole boundary $\xi$ at entrance and exit.

The horizontal and vertical beam envelopes for angle $\xi=29.5^{\circ}$ are shown in Fig. 7. Ideal beam envelopes are depicted as dashed lines and simulated beam is shown as solid lines.

\section{REFERENCES}

1. Dubrovin A.N. User's Guide MERMAID: Magnet Design in Two and Three Dimensions. SIM Limited, Novosibirsk Department. 1994. P.3-60.

2. Kukhtin V., Lamzin E., Sytchevsky S. Magnet Field Formation in Cyclotrons on the Basis of 3D Numerical Simulations // XXXIV Eur. Cyclotron Progress Meeting (ECPM 2006), Oct. 6-8, 2005. 